\title{
Crossed cerebellar diaschisis: a radiological finding in status epilepticus not to miss
}

\author{
Syed Amir Zaidi, ${ }^{1}$ Mian Ayaz ul Haq, ${ }^{1}$ Dorothea Bindman, ${ }^{1}$ Sachin Mathur ${ }^{2}$
}

${ }^{1}$ Department of Neurology, Royal Preston Hospital, Preston, UK ${ }^{2}$ Department of Neuroradiology, Royal Preston Hospital, Preston, UK

\section{Correspondence to}

Dr Syed Amir Zaidi, dramirzaidi@yahoo.com
CrossMark

To cite: Zaidi SA, Haq MA ul, Bindman D, et al. BMJ Case Rep Published online: [please include Day Month Year] doi:10.1136/bcr-2013200478

\section{DESCRIPTION}

A 43-year-old man was admitted to the intensive treatment unit with refractory status epilepticus. $\mathrm{He}$ was treated with intravenous benzodiazepines, phenytoin and levetiracetam. His EEG was consistent with status epilepticus. MRI of the brain showed a high signal change in T2-weighted images (not suppressed on fluid-attenuated inversion recovery (FLAIR)) in the right frontal lobe with inferior extension to the cingulate gyrus. Similar changes were also noted in the superior aspect of the left cerebellar hemisphere (figure 1). Diffusion-weighted images (DWI) showed gyral restriction of diffusion in the right frontal lobe and left cerebellar hemisphere (figure 2). The patient was readmitted with status epilepticus 6 weeks later. A repeat MRI showed resolution of previous high signal changes in the right frontal lobe but a new area of high signal was noted in the medial right parietal lobe (figure 3).Cerebral infarction may also cause diffusion restriction but resolution of previous hyperintense lesion was the pointer against the infarct.

Overall appearances in the right frontal lobe are in keeping with post seizure changes; the changes in the left cerebellar hemisphere are due to crossed cerebellar diaschisis (CCD).

CCD is characterised by hypometabolism and loss of functional activity in the cerebellar hemisphere contralateral to the supratentorial lesion.

It has been previously reported on positron emission tomography (PET) and single-photon emission CT (SPECT) scans of patients with stroke ${ }^{1}$ and supratentorial tumours but has rarely been described on MRI of patients with status epilepticus.
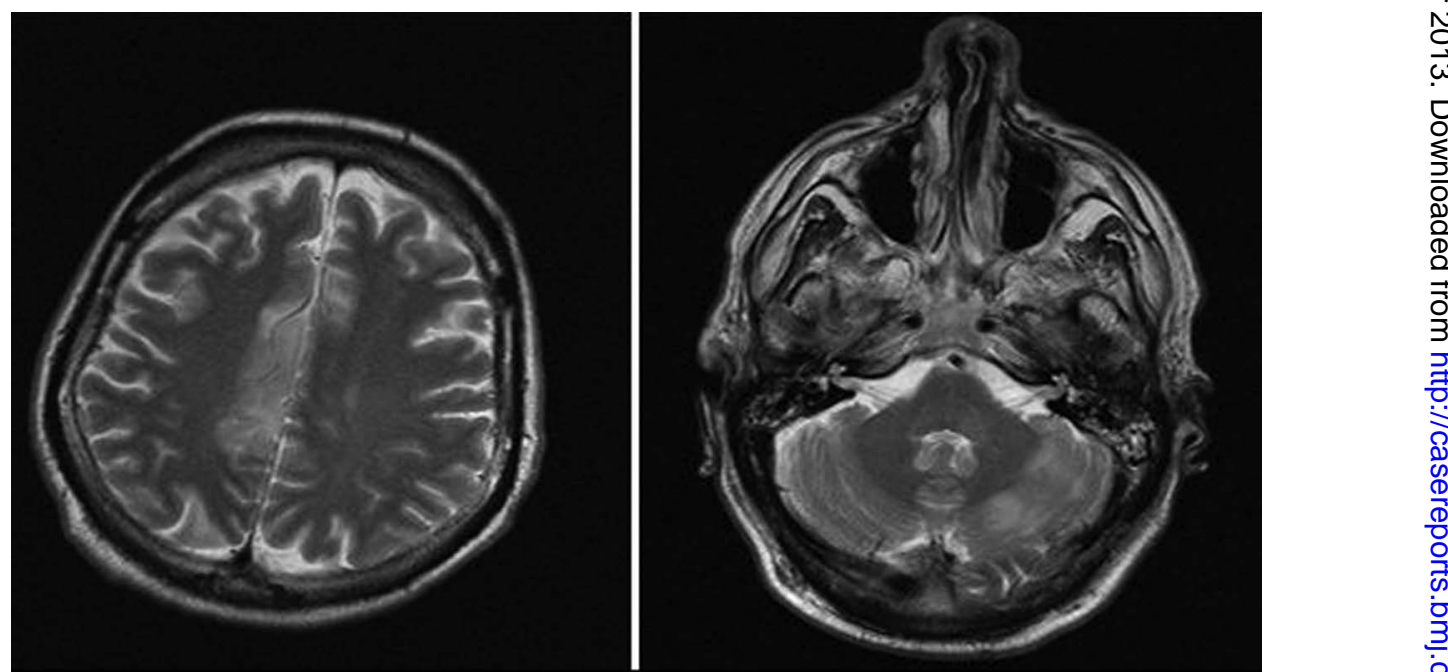


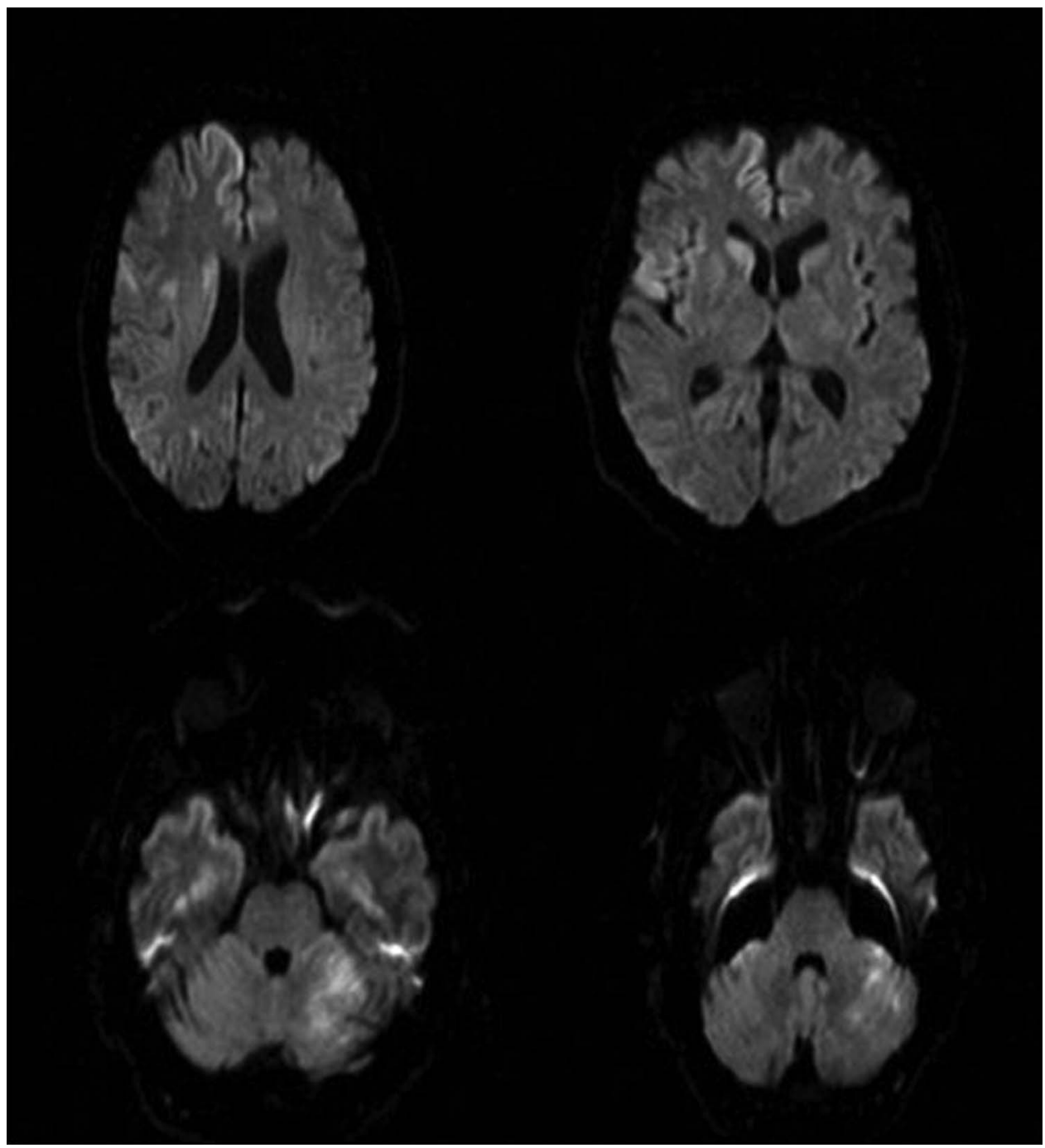

Figure 2 Diffusion weighted imaging showing restriction of diffusion in the right frontal lobe and the left cerebellar hemisphere.

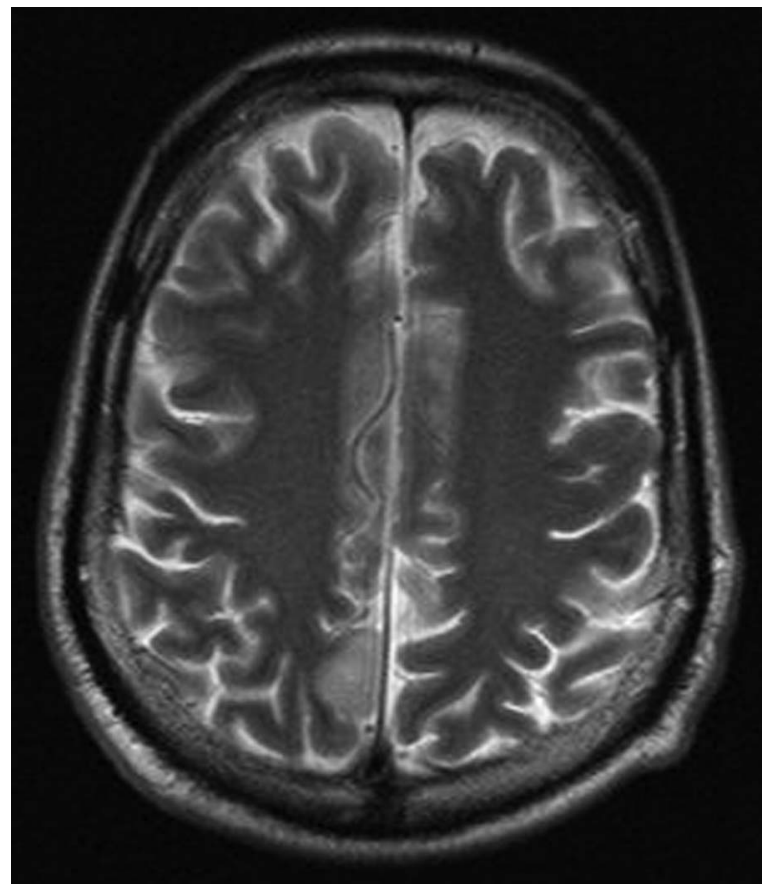

Figure 3 Resolution of previous right frontal lobe changes and new area of high signal in the right medial parietal lobe.
In the setting of status epilepticus, the excessive excitatory input from supratentorial epileptiform focus leads to the functional deactivation of the contralateral cerebellar hemisphere through the corticopontocerebellar pathway. ${ }^{2}$

MRI of the brain with DWI is a useful investigation to identify CCD in status epilepticus at an early stage. ${ }^{3}$

\section{Learning points}

- Crossed cerebellar diaschisis (CCD) refers to a depressed functional activity of the cerebellar hemisphere contra lateral to the supratentorial lesion.

- MRI techniques with diffusion weighted imaging (DWI) are useful to demonstrate the characteristic changes.

- CCD is usually a transient phenomenon and MRI lesions often resolve within a few weeks.

Contributors SAZ was involved in the literature review and editing of the manuscript. MAuH contributed in identifying the case and gathering the relevant clinical information. DB helped in editing the manuscript. SM reviewed the images and identified the most relevant images for the case with description of findings.

Competing interests None.

Patient consent Obtained. 
Provenance and peer review Not commissioned; externally peer reviewed.

\section{REFERENCES}

1 Baron JC, Bousser MG, Comar D, et al. Crossed cerebellar diaschisis in human supratentorial brain infarction. Trans Am Neurol Assoc 1981;105:459-61.
2 Samaniego EA, Stuckert E, Fischbein N, et al. Crossed cerebellar diaschisis in status epilepticus. Neurocrit Care 2010;12:88-90.

3 Tien RD, Ashdown BC. Crossed cerebellar diaschisis and crossed cerebellar atrophy: correlation of MR findings, clinical symptoms, and supratentorial diseases in 26 patients. AJR Am J Roentgenol 1992;158:1155-9.

Copyright 2013 BMJ Publishing Group. All rights reserved. For permission to reuse any of this content visit

http://group.bmj.com/group/rights-licensing/permissions.

BMJ Case Report Fellows may re-use this article for personal use and teaching without any further permission.

Become a Fellow of BMJ Case Reports today and you can:

- Submit as many cases as you like

- Enjoy fast sympathetic peer review and rapid publication of accepted articles

- Access all the published articles

- Re-use any of the published material for personal use and teaching without further permission

For information on Institutional Fellowships contact consortiasales@bmjgroup.com

Visit casereports.bmj.com for more articles like this and to become a Fellow 